\title{
Predictors of outcome in penetrating gastric injuries
}

\author{
Zulfu Arikanoglu, Fatih Taskesen, Akin Onder, Murat Kapan, Ibrahim Aliosmanoglu, Mesut Gul, Yusuf Çelik, \\ Omer Basol, Sadullah Girgin
}

Dicle University, Diyarbakir, Turkey

Prz Gastroenterol 2013; 8 (4): 237-242

DOI: $10.5114 / p g .2013 .37485$

Key words: penetrating gastric injury, morbidity, logistic model.

Address for correspondence: Assist. Prof. Zulfu Arikanoglu, Department of General Surgery, School of Medicine, Dicle University, 21280 Diyarbakir, Turkey, phone: +90-412.248-8001 (4754), e-mail: zulfuarikanoglu@gmail.com

\begin{abstract}
Introduction: Both solid and hollow organs are open to injury in penetrating abdominal trauma. Morbidity and mortality related to gastric injury in penetrating abdominal trauma are uncommon. Isolated gastric injuries occur less frequently.

Aim: To examine the morbidity associated with penetrating gastric injuries.

Material and methods: Data for 45 patients collected between 2000 and 2010 were analyzed retrospectively. The patients were grouped as those with isolated gastric injuries and those with concomitant organ injuries, and then grouped according to the presence of complications. Logistic regression was used to determine the independent predictors of morbidity following gastric injury.

Results: The sample comprised 40 males (88.9\%) and 5 females (11.1\%), with a mean age of $28.56 \pm 11.66$ (range 15-75) years. The mechanism of injury was stab wounds in 26 patients and gunshot wounds in the remainder. Mortality was $8.9 \%$ (4/45 patients). The forward stepwise binary logistic regression analysis of the results revealed three risk variables: 2 patient measures (injury severity score and number of injured intra-abdominal organs) and the mechanism of injury. The odds ratios and confidence intervals for the three variables were 3.74 (2.40-5.83), 3.41 (1.60-7.28), and 3.00 (1.96-4.59), respectively.

Conclusions: We identified the risk factors for morbidity in penetrating gastric injuries using a binary logistic model.
\end{abstract}

\section{Introduction}

Penetrating trauma to the stomach is more common than blunt trauma [1]. Gastric injuries occur in $7-20 \%$ of patients with penetrating abdominal trauma, and are usually accompanied by injuries to other organs [2-7]. Isolated gastric injuries occur less frequently $[3,8]$.

Morbidity and mortality related to gastric injury in penetrating abdominal trauma are infrequent, occurring in $6 \%$ and $0.4 \%$ of patients, respectively. Morbidity and mortality in patients with gastric injury are usually the result of associated injuries [3].

\section{Aim}

This study evaluated the factors resulting in the morbidity of penetrating gastric injury using a binary logistic model.

\section{Material and methods}

Forty-five patients with penetrating abdominal trauma treated at the General Surgery Department of Dicle
University Medical School between January 2005 and December 2010 were evaluated retrospectively. The age and sex of the patients, causes of injury, occurrence and duration of shock, length of hospital stay (LOS), intraabdominal organ injuries, injuries of associated systems, injury severity score (ISS), treatment methods, and causes of morbidity and mortality were recorded for each patient using pre-prepared forms. The patients were divided into two groups: group 1 comprised isolated gastric injuries and group 2 consisted of patients with gastric injuries accompanied by injuries to other abdominal organs. Subsequently, the patients were divided into those with and without complications. They were compared in terms of age, sex, cause of injury, preoperative time, hypotension, ISS, and LOS.

All patients underwent fluid resuscitation on admission. The hemodynamic status was determined using the heart rate and systolic blood pressure on admission. Patients with a heart rate $<100$ beats per minute and a systolic blood pressure $>90 \mathrm{~mm} \mathrm{Hg}$ were defined as hemodynamically stable, whereas those with a heart 
rate $>100$ beats per minute and systolic blood pressure $<90 \mathrm{~mm} \mathrm{Hg}$ were defined as unstable. All patients were resuscitated in the emergency room. Patients who were hemodynamically unstable despite resuscitation underwent rapid laparotomies without further diagnostic tests, whereas consultations and the necessary tests related to concomitant injuries were carried out in those who were hemodynamically stable. Stable patients who were observed to have an intact peritoneum during local wound exploration were simply observed. All gunshot wounds (GSWs) in the stomach area were operated on, whereas the indications for surgery in stab wounds were the presence of omentum or organ evisceration, hypovolemic shock (systolic blood pressure $<90 \mathrm{~mm} \mathrm{Hg}$, heart rate $>100$ beats/min), acute abdominal findings on physical examination, and positive results of local wound exploration, laboratory tests, and radiological examinations. Patients who were managed conservatively after penetrating abdominal trauma and those who underwent explorative laparotomies or damagecontrol surgery were excluded from the study. Preoperatively, all patients underwent a detailed physical examination, complete blood count, anteroposterior chest

Table I. Clinical characteristics of 45 patients with penetrating gastric trauma

\begin{tabular}{|c|c|}
\hline Gender (M/F) & $40 / 5$ \\
\hline Age, $\bar{x} \pm \mathrm{SD}$, range [years] & $28.56 \pm 11.66,15-75$ \\
\hline \multicolumn{2}{|l|}{ Mechanism of injury, $n(\%)$} \\
\hline GSW & $19(42.2)$ \\
\hline SW & $26(57.8)$ \\
\hline \multicolumn{2}{|l|}{ Localization, $n$ (\%) } \\
\hline Anterior & $26(57.8)$ \\
\hline Anterior-posterior & $19(42.2)$ \\
\hline Presurgery time, $\bar{x} \pm \mathrm{SD}$, range $[\mathrm{h}]$ & $2.16 \pm 1.02,1-5$ \\
\hline \multicolumn{2}{|l|}{ Systolic blood pressure, $n(\%)$} \\
\hline Stable & $42(93.3)$ \\
\hline Unstabil & $3(6.7)$ \\
\hline Shock, $n(\%)$ & $3(6.7)$ \\
\hline \multicolumn{2}{|l|}{ Hemoglobin, $n(\%)[\mathrm{mg} / \mathrm{dl}]$} \\
\hline$>10$ & $41(91.1)$ \\
\hline$<10$ & $4(8.9)$ \\
\hline ISS, $\bar{x} \pm$ SD, range & $9.87 \pm 6.43,4-25$ \\
\hline \multicolumn{2}{|l|}{ Complication, $n$ (\%) } \\
\hline Present & $12(26.7)$ \\
\hline Absent & $33(73.3)$ \\
\hline $\begin{array}{l}\text { The average length of hospital stay, } \\
\bar{x} \pm \text { SD, range [days] }\end{array}$ & $10.78 \pm 5.76(0-28)$ \\
\hline Mortality, $n(\%)$ & $4(8.9)$ \\
\hline
\end{tabular}

X-ray, and direct abdominal X-ray in the standing position. The ISS was used to grade the severity of the injury, according to the description by Van Nata et al. [9].

\section{Statistical analysis}

All continuous variables are presented as means and standard deviations, and all categorical variables are presented as numbers of patients and percentages. The medians of the two groups were compared using the Mann-Whitney U-test. Categorical variables were analyzed using Fisher's exact test or the $\chi^{2}$ test. Binary logistic regression analysis was performed to obtain the risk ratios (odds ratios) of predictors of morbidity. A forward stepwise procedure was performed for the binary logistic regression. For all statistical analyses, $p \leq 0.05$ was considered significant. The SPSS software was used to perform all statistical analyses (ver. 15.0; SPSS Inc., Chicago, IL, USA).

\section{Results}

In total, 968 patients underwent various surgical procedures because of penetrating abdominal trauma at the General Surgery Department of Dicle University Medical School between January 2005 and December 2010. Of these, 45 (4.64\%) had gastric injuries.

Table II. Frequency of the additional organ injuries injury in group II patients treated for penetrating gastric injury

\begin{tabular}{|c|c|c|}
\hline Intraabdominal & No. of patients & Percentage \\
\hline Duodenum & 2 & 5 \\
\hline Small bowel & 9 & 22.5 \\
\hline Colon & 7 & 17.5 \\
\hline Liver & 5 & 12.5 \\
\hline Spleen & 4 & 10 \\
\hline Pancreas & 1 & 2.5 \\
\hline Gallbladder & 2 & 5 \\
\hline Kidney & 2 & 5 \\
\hline Bladder & 2 & 5 \\
\hline Diaphragm & 4 & 10 \\
\hline Major vessels & 2 & 5 \\
\hline Extraabdominal & No. of patients & $\%$ \\
\hline Head-neck & 1 & 10 \\
\hline Chest & 4 & 40 \\
\hline Upper extremity & 1 & 10 \\
\hline Lower extremity & 1 & 10 \\
\hline Pelvic fracture & 3 & 30 \\
\hline
\end{tabular}


Table III. Distribution and statistical comparison of group properties

\begin{tabular}{|c|c|c|c|}
\hline Parameter & Group 1 & Group 2 & Value of $p$ \\
\hline Gender, $n(\%)$ & & & NS \\
\hline Female & 0 & $5(19.2)$ & \\
\hline Male & $19(100)$ & $21(80.8)$ & \\
\hline Age, $\bar{x} \pm S D$, range [years] & $30.11 \pm 16.18,15-75$ & $27.42 \pm 6.91,15-40$ & NS \\
\hline Presurgery time, $\bar{x} \pm S D$, range $[h]$ & $2.32 \pm 1.16,1-5$ & $2.04 \pm 0.91,1-4$ & NS \\
\hline Systolic blood pressure, $n(\%)$ & & & NS \\
\hline Stable & 19 (100) & $23(88.5)$ & \\
\hline Unstable & - & $3(11.5)$ & \\
\hline Mechanism of injury, $n(\%)$ & & & 0.002 \\
\hline GSW & $3(15.8)$ & $16(61.5)$ & \\
\hline SW & $16(84.2)$ & $10(38.5)$ & \\
\hline Localization & & & 0.014 \\
\hline Anterior & $15(78.9)$ & $11(42.3)$ & \\
\hline Anterior-posterior & $4(21.1)$ & $15(57.7)$ & \\
\hline Shock, $n(\%)$ & - & $3(11.3)$ & NS \\
\hline Duration of shock [h]: & & & NS \\
\hline $0-1$ & - & $3(11.5)$ & \\
\hline $2-3$ & - & $1(3.8)$ & \\
\hline \multicolumn{4}{|l|}{ Hemoglobin level: } \\
\hline Normal & $18(94.7)$ & $23(88.5)$ & NS \\
\hline Low & $1(5.3)$ & $3(11.5)$ & \\
\hline ISS, $\bar{x} \pm$ SD, range & $5.63 \pm 3.53,4-16$ & $12.96 \pm 6.35,4-25$ & $<0.001$ \\
\hline Complication, $n(\%)$ & $2(10.5)$ & $10(38.50)$ & 0.036 \\
\hline LOS, $\bar{x} \pm \mathrm{SD}$, range $[$ days] & $8.37 \pm 4.62,5-25$ & $12.53 \pm 5.94$ & 0.015 \\
\hline Number of complication, $\bar{x} \pm$ SD & $0.11 \pm 0.32$ & $0.77 \pm 1.07$ & 0.023 \\
\hline Mortality, n (\%) & - & $4(15.38)$ & NS \\
\hline
\end{tabular}

Group 1 - isolated injury to the stomach, group 2 - associated with abdominal organ injury, ISS - injury severity score, GSW - gunshot wound, SW - stab wound, LOS - length of hospital stay, NS - not significant

Of the patients with gastric injury, 40 (89\%) were male and 5 (11\%) were female, with a mean age of 28.56 \pm 11.66 (range 15-75) years. Gunshot wounds caused $42.2 \%$ of the penetrating gastric injuries. Anterior wall injuries were found in 26 patients (57.8\%). Complications were identified in 12 patients. The mean ISS was $9.87 \pm 6.43$ (range $4-25$ ). The mortality rate was $8.9 \%$ $(n=4)$. The general characteristics of the patients are summarized in Table I.

The most commonly associated injured intraabdominal organs were the small bowel (22.5\%) and colon (17.5\%), and the most commonly associated injured extra-abdominal organs were the chest (40\%) and pelvis (30\%). The distribution of additional organ injuries is presented in Table II.

Patients with additional organ injuries were classified as group 2. The sample comprised 19 (42.2\%) pa-
Table IV. Distribution of the complications

\begin{tabular}{lcc} 
Complications & Group I $(n=19)$ & Group II $(n=26)$ \\
\hline Intra-abdominal abscess & 1 & 2 \\
\hline Wound infection & 2 & 8 \\
\hline Atelectasis & 1 & 3 \\
\hline Pneumonia & None & 2 \\
\hline Empyema & None & 2 \\
\hline Sepsis & None & 1 \\
\hline Multi-organ failure & None & 1 \\
\hline Total & 4 & 19
\end{tabular}

tients in group 1 and 26 (57.8\%) patients in group 2. Sex, age, time before surgery, shock, and duration of shock did not differ significantly between the two groups $(p>0.05)$. The mechanism of injury (MI), location, ISS, 
Table V. Distribution and statistical comparison of group with complication or without complication

\begin{tabular}{|c|c|c|c|}
\hline Parameter & With complication & Without complication & Value of $p$ \\
\hline Gender & & & 0.109 \\
\hline Female, $n(\%)$ & $3(25)$ & $2(6)$ & \\
\hline Male (\%) & $9(75)$ & $31(94)$ & \\
\hline Age, $\bar{x} \pm S D$, range [years] & $24.91 \pm 7.31,15-40$ & $29.87 \pm 12.72,15-75$ & 0.211 \\
\hline Presurgery time, $\bar{x} \pm S D$, range [h] & $2.00 \pm 0.95,1-3$ & $2.21 \pm 1.05,1-5$ & 0.544 \\
\hline Systolic blood pressure, $n$ (\%) & & & 1.00 \\
\hline Stable & $11(91.6)$ & $31(94)$ & \\
\hline Unstable & $1(8.4)$ & $2(6)$ & \\
\hline Mechanism of injury, $n$ (\%) & & & 0.045 \\
\hline GSW & $8(66.6)$ & $11(33.4)$ & \\
\hline SW & $4(33.4)$ & $22(66.6)$ & \\
\hline Localization, $n$ (\%) & & & 1.00 \\
\hline Anterior & $7(58.3)$ & $19(57.6)$ & \\
\hline Anterior-posterior & $5(41.7)$ & $14(42.4)$ & \\
\hline \multicolumn{4}{|l|}{ Shock, $n(\%)$} \\
\hline Present & $11(91.6)$ & $31(94)$ & 1.00 \\
\hline Absent & $1(8.4)$ & $2(6)$ & \\
\hline \multicolumn{4}{|l|}{ Hemoglobin level, $n(\%)$} \\
\hline Normal & $11(91.6)$ & $30(91)$ & NS (1.00) \\
\hline Low & $1(8.4)$ & $3(9)$ & \\
\hline ISS, $\bar{x} \pm \mathrm{SD}$, range & $14.33 \pm 5.89,9-25$ & $8.24 \pm 5.90,4-25$ & 0.004 \\
\hline LOS, $\bar{x} \pm \mathrm{SD}$, range [days] & $17.66 \pm 4.81,12-28$ & $8.27 \pm 3.65,0-17$ & $<0.001$ \\
\hline \multicolumn{4}{|l|}{ Group, $n(\%)$} \\
\hline I & $2(16.6)$ & $17(51.52)$ & 0.036 \\
\hline$\|$ & $10(83.34)$ & $16(48.48)$ & \\
\hline \multicolumn{4}{|l|}{ Mortality, $n(\%)$} \\
\hline Yes & $2(16.66)$ & $31(94)$ & NS $(0.286)$ \\
\hline No & $10(83.34)$ & $2(6)$ & \\
\hline Extra-abdominal organ injury, $n(\%)$ & & & 0.448 \\
\hline Present & $4(33.34)$ & $7(21.21)$ & \\
\hline Absent & $8(66.66)$ & $26(78.79)$ & \\
\hline $\mathrm{NIO}, \bar{x} \pm \mathrm{SD}$, range & $1.66 \pm 0.98,0-3$ & $0.5 \pm 0.75,0-3$ & $<0.001$ \\
\hline
\end{tabular}

Group 1 - isolated injury to the stomach, group 2 - associated with abdominal organ injury, ISS - injury severity score, GSW - gunshot wound, SW - stab wound, LOS - length of hospital stay, NS - not significant, NIO - number of intra-abdominal injured organs

Table VI. The outcomes of logistic regression

\begin{tabular}{lcccccc} 
Variable & $\beta$ & SE & Odds & $95 \% \mathrm{Cl}$ & Wald & Value of $p$ \\
\hline ISS & 1.321 & 0.226 & 3.74 & $2.40-5.83$ & 34.16 & 10.13 \\
\hline NIO & 1.229 & 0.386 & 3.41 & $1.60-7.28$ & $<.001$ \\
\hline MI & 1.100 & 0.217 & 3.00 & $1.96-4.59$ & 25.69
\end{tabular}

$\beta$-coefficient regression, SE-standard error, Odds-odds coefficient, 95\% Cl-confidence interval predicted at the $95 \%$, Wald - the value of Wald statistics, $p$ - the level significant, NIO - number of intra-abdominal injured organs, MI - the mechanism of injury, ISS - injury severity score 
complications, and LOS differed significantly between the groups $(p<0.05)$. The two groups are summarized in Table III. As shown in Table III, the complication rates differed significantly between groups 1 and 2 (16.6\% vs. $83.34 \% ; p=0.036)$. The most frequent complication was wound infection. The distribution of the complications is shown in Table IV.

As Table $V$ shows, GSW, ISS, group, LOS, extraabdominal organ injury, and number of intra-abdominal injured organs (NIO) were significantly higher in patients with complications $(p<0.05)$.

The outcome of the logistic regression model is presented Table VI, which shows that ISS, NIO, and MI were significant predictors of morbidity $(p<0.001)$. The odds ratios and $95 \%$ confidence intervals of these three variables were 3.74 (2.40-5.83), 3.41 (1.60-7.28), and 3.00 (1.96-4.59), respectively.

\section{Discussion}

Both solid and hollow organs are open to injury in penetrating abdominal trauma. The most frequently injured solid organ is the liver (19\%), and the most frequently injured hollow organ is the small intestine (30\%). These organs are closely followed by the colon (18\%), stomach (7-20\%), pancreas, and duodenum $[5,8,10-12]$. Isolated gastric injuries due to abdominal trauma are rare; gastric injuries are usually accompanied by abdominal or extra-abdominal organ injuries [7, 10, 13]. As in our study, the most frequently reported accompanying injured abdominal organs are the small intestine and colon, and the most frequently injured extra-abdominal organs are the lungs and pelvis [14].

Although gastric injuries most frequently involve the anterior wall (40\%), they may also be observed in the greater curvature $(23 \%)$, lesser curvature $(15 \%)$, posterior wall (15\%), gastroesophageal junction (7\%), and pylorus (7\%) [15-18]. All of our patients had anterior gastric wall injuries, and $42.2 \%$ also had posterior wall injuries. Therefore, when an injury to any part of the stomach wall is detected, a detailed intraoperative exploration should be performed to rule out injuries to other parts of the gastric wall [1, 19-21]. The morbidity rate in gastric injuries related to penetrating trauma is approximately $6 \%$. The position of the stomach within the abdomen, thickness of its wall, rich arterial supply, and its low bacterial content have been suggested as reasons for the low morbidity rate [3, 8, 20, 22].

The $\mathrm{MI}$ influences morbidity $[7,10]$. In our study, the $\mathrm{MI}$ was also an important predictor of morbidity due to the high-energy nature of GSWs, the organ damage frequently accompanying the injury, and the fact that these are usually multiple injuries.
The ISS, which we used as a trauma score, was a predictor identified in our study. The ISS is the scoring system most commonly applied to patients with trauma involving more than one organ. Most studies have demonstrated a good correlation between survival and the ISS [23]. Mortality significantly parallels an increase in the ISS [24]. The ISS is usually low in gastric injuries caused by penetrating trauma [10]. In our patients, the mean ISS differed significantly between those with and without complications and between those with and without mortality ( $p<0.05$; Figure 1 ).

The ISS assesses the single organ with the highest score among the intra-abdominal organs injured [25]. However, the method does not supply information on the number of injured organs, which we found to predict morbidity. A greater degree of hemorrhage, higher risk for intra-abdominal contamination, or higher ISS might be among the factors leading to this outcome [26].

Mortality is significantly higher in trauma patients older than 50 years, even in the absence of concomitant disease. However, $78 \%$ of all deaths between the ages of 15 and 24 years are due to trauma [27]. In our study, most patients with penetrating gastric trauma were young adult males, concurring with the findings of previous reports $[14,28]$. Similarly, age and sex were not associated with the outcome of penetrating gastric injury in this study.

In gastric injuries related to penetrating trauma, an early diagnosis is the most important step to minimize morbidity and mortality. The diagnosis can be based on vital signs, clinical presentation, physical examination, plain-film chest X-ray (signs of pneumoperitoneum), abdominal ultrasound, computed tomography, laparoscopy, or exploratory laparotomy. The clinical presentation of gastric injuries usually involves abdominal pain, peritoneal irritation, or findings related to the concomitant organ injuries [15, 17].

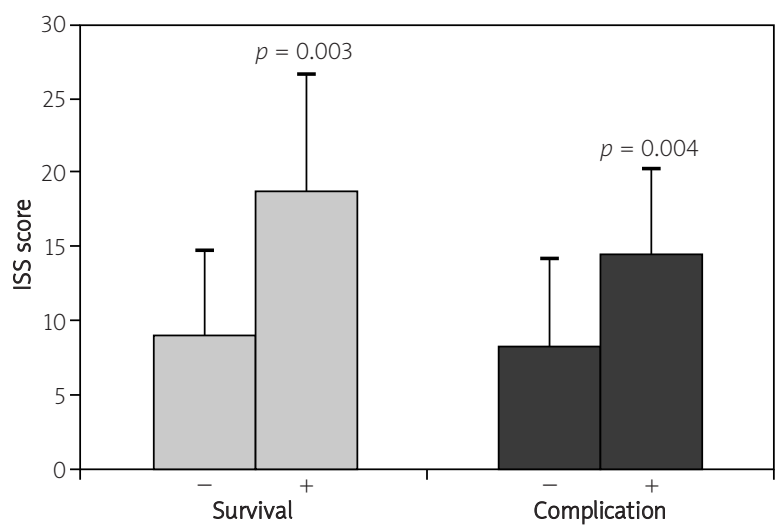

Fig. 1. The mean $(\bar{x})$ and standard deviation (SD) of survival and non-survival, complication and non-complication of ISS values 
The reported mortality rates range from $0.4 \%$ to $17 \%$, reflecting the variety in presentation $[3,8,19]$. Isolated gastric injuries are rare and are associated with low morbidity and mortality rates $[3,10]$. In this study, no mortality was observed in patients with isolated gastric injuries and all four patients who died had concomitant organ injuries; however, this difference in mortality between the two groups was not significant.

Although primary repair with debridement of the wound edges is adequate for stab wounds and lowvelocity GSWs due to the thick muscle layer of the stomach and its rich arterial supply, larger injuries may occur to the stomach in high-velocity GSWs due to the shockwave phenomenon. Such injuries may require more extensive debridement or a partial gastrectomy [1, 3, 8, $14,29,30]$. In addition, care must be taken regarding postoperative strictures in injuries to the gastroesophageal junction or pylorus. All patients in our study underwent primary repairs and no stricture developed in any patient.

\section{Conclusions}

Isolated gastric injuries can be treated with a low complication rate. In our series, ISS, NIO, and MI predicted the development of complications due to penetrating gastric injury based on logistic regression analysis.

\section{References}

1. Lawson HH. Injuries to the stomach. South Afr J Surg 1989; 27: 60-1.

2. Dawidson I, Miller E, Litwin MS.Gunshot wounds of the abdomen: a review of 277 cases. Arch Surg 1976; 111: 862-5.

3. Durham RM, Olson S, Weigelt JA. Penetrating injuries to the stomach. Surg Gynecol Obstet 1991; 172: 298-302.

4. Feliciano DV, Burch JM, Spjut-Patrinely V, et al. Abdominal gunshotwounds. An urban trauma center's experience with 300 consecutive patients. Ann Surg 1988; 208: 362-70.

5. Boylu Ș, Taçyıldız H. Penetrating injuries of the stomach and esophagus. Ulus Travma Acil Cerrahi Derg 1997; 3: 181-4.

6. Addly J, Ali S, Lee J, et al. Endoscopic clip closure of penetrating stabwound to stomach. Endoscopy 2008; 40: 219-20.

7. Madiba TE, Hlophe M. Gastric trauma: a straight forward injury, but no room for complacency. SAJS 2008; 46: 10-3.

8. Espinoza R, Rodríguez A. Traumatic and non-traumatic perforation of hollow viscera. Surg Clin North Am 1997; 77: 1291-304.

9. Van Nata TL, Morris JA Jr. Injury scoring and trauma outcomes. In: Trauma. $4^{\text {th }}$ ed. Mattox KL, Feliciano DV, Moore EE (eds). McGraw-Hill, New York 2000; 69-78.

10. Edelman DA, White MT, Tyburski JG, et al. Factors affecting prognosis in patients with gastric trauma. Am Surg 2007; 73: 48-53.

11. Uludağ $M$, Yetkin $G$, Citgez B, et al. Effects of additional intraabdominal organ injuries in patients with penetrating small bowel trauma on morbidity and mortality. Ulus Travma Aci Cerrahi Derg 2009; 15: 45-51.
12. Dongo AE, Kesieme EB, Irabor DO, et al. A review of posttraumatic bowel injuries in Ibadan. ISRN Surg 2011; 2011: 478042. doi:10.5402/2011/478042.

13. Ohene-Yeboah M, Dakubo JCB, Boakye F, et al. Penetrating abdominal injuries in adults seen at two teaching hospitals in ghana. Ghana Med J 2010; 44: 103-8.

14. Rodríguez-Hermosa JI, Roig J, Sirvent JM, et al. Gastric perforations from abdominal trauma. Dig Surg 2008; 25: 109-16.

15. Baker SP, O'Neill B, Haddon W Jr, et al. The injury severity score: a method for describing patients with multiple injuries and evaluating emergency care. J Trauma 1974; 14: 187-96.

16. Shinkara $\mathrm{H}$, Yasuhara $\mathrm{H}$, Naka S, et al. Characteristic features of abdominal organ injuries associated with gastric rupture in blunt abdominal trauma. Am J Surg 2004; 187: 394-7.

17. Tejerina EE, Holanda MS, Lopez-Espadas F, et al. Gastric rupture from abdominal trauma. Injury 2004; 35: 228-31.

18. Nanji SA, Mock C. Gastric rupture resulting from abdominal trauma and requiring gastric resection. J Trauma 1999; 47: 410-2.

19. Wilkinson AE. Injuries to the stomach. An analysis of 95 cases. South Afr J Surg 1989; 27: 59-60.

20. Gorbach SL. Intestinal microflora. Gastroenterology 1979; 60: 1110-29.

21. Yajko RD, Seydel F, Trimble C. Rupture of the stomach from blunt abdominal trauma. J Trauma 1975; 15: 177-83.

22. Hill N. Normal and pathologgial flora of the upper gastrointestinal tract. Scand J Gastroenterol 1985; 111 (Suppl): 1-5.

23. Eryılmaz M, Durusu M, Menteș Ö, et al. Comparison of trauma scores for adults who fell from height as survival predictivity. Turk J Med Sci 2009; 39: 247-52.

24. İnce $\mathrm{H}$, Ince N, Taviloğlu K, et al. A different approach to trauma scoring. Ulus Travma Acil Cerrahi Derg 2006; 12: 195-200.

25. Domingues de A, de Sousa RM, Nogueira Lde S, et al. The role of the New Trauma and Injury Severity Score (NTRISS) for survival prediction. Rev Esc Enferm USP 2011; 45: 1353-8.

26. Larson CR, White CE, Spinella PC, et al. Association of shock, coagulopathy, and initial vital signs with massive transfusion in combat casualties. J Trauma 2010; 69: 26-32.

27. Morris JA, McKenzie EJ, Edelstein SL. The effect of preexisting conditions onn mortality in trauma patients. JAMA 1990; 263: 1942-6.

28. Bruscagin V, Coimbra R, Rasslan S, et al. Blunt gastric injury. A multicentre experience. Injury 2001; 32: 761-4.

29. Chu CC, Moncrief G. An in vitro evaluation of the stability of mechanical properties of surgical sutures in various $\mathrm{pH}$ conditions. Ann Surg 1983; 198: 223-8.

30. Durham R. Management of gastric injuries. Surg Clin North Am 1990; 70: 517-7. 